\title{
The bowing potential of granitic rocks: rock fabrics, thermal properties and residual strain
}

\author{
S. Siegesmund $\cdot$ S. Mosch $\cdot$ Ch. Scheffzük $\cdot$ \\ D. I. Nikolayev
}

Received: 11 September 2007/ Accepted: 16 October 2007/Published online: 14 November 2007

(c) Springer-Verlag 2008

\begin{abstract}
The bowing of natural stone panels is especially known for marble slabs. The bowing of granite is mainly known from tombstones in subtropical humid climate. Field inspections in combination with laboratory investigations with respect to the thermal expansion and the bowing potential was performed on two different granitoids (Cezlak granodiorite and Flossenbürg granite) which differ in the composition and rock fabrics. In addition, to describe and explain the effect of bowing of granitoid facade panels, neutron time-of-flight diffraction was applied to determine residual macro- and microstrain. The measurements were combined with investigations of the crystallographic preferred orientation of quartz and biotite. Both samples show a significant bowing as a function of panel thickness and destination temperature. In comparison to marbles the effect of bowing is more pronounced in granitoids at temperatures of $120^{\circ} \mathrm{C}$. The bowing as well as the thermal expansion of the Cezlak sample is also anisotropic with respect to the rock fabrics. A quantitative estimate was performed based on the observed textures. The effect of the locked-in stresses may also have a control on the bowing together with the thermal
\end{abstract}

S. Siegesmund $(\varangle) \cdot$ S. Mosch

Geoscience Centre, University Göttingen,

Goldschmidtstrasse 3, 37077 Göttingen, Germany

e-mail: ssieges@gwdg.de

Ch. Scheffzük

Freie Universität Berlin, FB Geowissenschaften,

Malteserstrasse 74-100, 12249 Berlin, Germany

Ch. Scheffzük · D. I. Nikolayev

Frank Laboratory of Neutron Physics,

JINR Dubna, 141980 Dubna, Russia stresses related to the different volume expansion of the rock-forming minerals.

Keywords Granitoids - Bowing - Residual strain · Texture $\cdot$ Thermal expansion

\section{Introduction}

Dimensional stones have been used as thin veneer cladding for a long time. The durability of such thin slabs (mostly $30-40 \mathrm{~mm}$ ) is satisfactory at most constructions. However, on several buildings all over the world, the long-term deformation such as expansion and bowing of claddings is meanwhile well known from marbles. Up to now, the knowledge about the causes of this most spectacular deterioration feature of marble is still under discussion although it was frequently reported from ancient gravestones (e.g., Grimm 1999). It seems to be generally clear that this weathering process is due to anomalous expansion-contraction behaviour of calcite (e.g., Kessler 1919; Rosenholtz and Smith 1949; Sage 1988; Siegesmund et al. 2000). Thermally treated marbles, which do not return to the initial length change after cooling, can show a residual stress even as a result of small temperature changes between 20 and $50^{\circ} \mathrm{C}$ (Battaglia et al. 1993; Widhalm et al. 1996; Zeisig et al. 2002, etc.). Logan et al. (1993) explained the bowing of marble slabs as a result of the thermal expansion of calcite together with the release of locked residual stresses. Winkler (1996) favoured the role of moisture since continuous rows of ordered water molecules may cause swelling by elongation and stone disruption because the damage under dry conditions is restricted to up to four heating-cooling cycles (e.g., Koch and Siegesmund 2004). Recently, bowing of panels made 
from granites (Fig. 1), limestones or conglomerates like the porous "Brannenburger Nagelfluh" was reported (Grimm 1999; Winkler 1996). Winkler (1996) proposed that bowing of granite veneer panels shares some of the complex factors with marble panels, such as the action of moisture dilatation, stress relief and moisture action by microcracking by the excessive contraction of the quartz crystals during cooling.

To demonstrate the effect of environmental impacts on the bowing of granites, a detailed study on two selected samples often used as cladding material was performed. Different approaches were applied for the characterization of the type and degree of bowing. Thermal expansion measurements were performed to investigate the combined effect of heating and cooling on the decay of granites. The bowing potential was also investigated by artificial weathering as a function of panel thickness and temperature. All the experimental work was done with respect to the rock fabric to quantify the deterioration rate. Additionally, the locked in stress-that is stress generated during the geological history of the rock-was examined by residual strain measurements applying neutron time-offlight diffraction. This technique was successfully applied to describe the bowing behaviour of marbles (Scheffzük et al. 2007).

\section{Samples}

The bowing potential of granitic rocks was investigated on two granitoids, which differ in mineralogical composition and rock fabrics. One sample (Cezlak granodiorite; SLO; Fig. 2a) originates from the Pohorje complex in N-Slovenia, near Oplotnica (for details see, e.g., Márton et al.
2006). The other one is the Flossenbürg granite (FG, Fig. 2b), a late-Variscan granite from NE-Bavaria, Germany (for details see Vollbrecht et al. 1991).

\section{Cezlak granodiorite}

In the central part of the Pohorje magmatic massive a $\sim 40 \mathrm{~km}$ long and $7 \mathrm{~km}$ wide calc alkaline igneous complex crops out that was emplaced into a polymetamorphic basement (Márton et al. 2006). In the SE of this complex a grey granodiorite is quarried, which is characterized by cross cutting of light aplitic and pegmatitic veins of different generations. In general the rock shows a medium grained texture with a macroscopically visible foliation that is mainly defined by the alignment of biotite and elongated quartz crystals. Quartz, plagioclases and Kfeldspars are the major minerals in the granodiorite. The modal composition is (in \%): plagioclase 50-60, orthoclase 5-10, quartz 20-30, biotite 10-15, and accessories. In general the minerals show hypidiomorphic shapes. Multiple zoning of feldspar can be observed frequently. Quartz crystals rarely show regular grain boundaries. More common are bands of recrystallized quartz grains and other structures indicating dynamic recrystallization. For detailed studies about petrography see, e.g., Zupančič (1994).

Quartz and biotite exhibit a significant lattice preferred orientation which was obtained by $U$-stage measurements using three mutually perpendicular oriented thin sections (Fig. 3). The poles of biotite (001)-cleavage planes show a girdle pattern around the $[x]$-axis with submaxima parallel and perpendicular to the foliation. The distribution of the quartz $[c]$-axis is less pronounced and shows a weak broad girdle pattern with some submaxima.
Fig. 1 Cezlak Granodiorite: a used as panels (size of slabs: mainly $1,700 \times 375 \times 20 \mathrm{~mm}$, Maxi-Market, Ljubljana). b Detail of a W-facade showing clearly the phenomena of bowing. The texture of the rock was not considered during cutting process

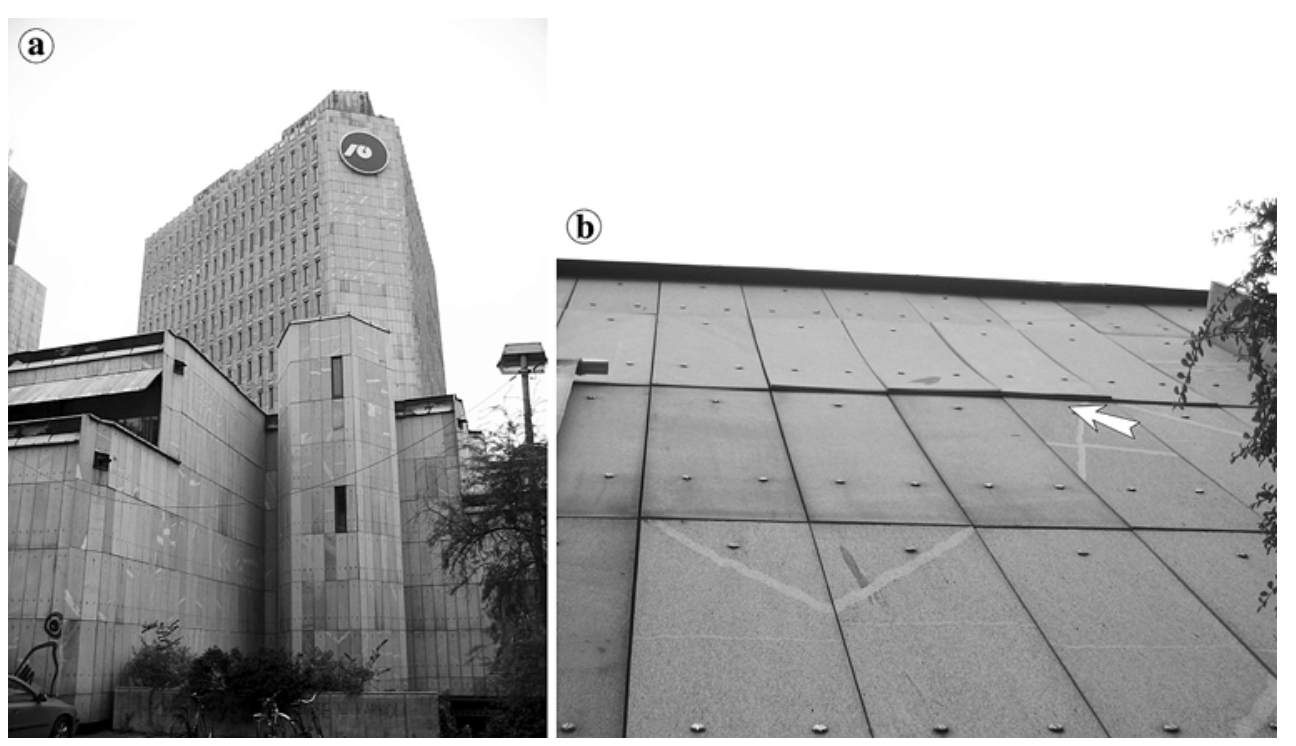




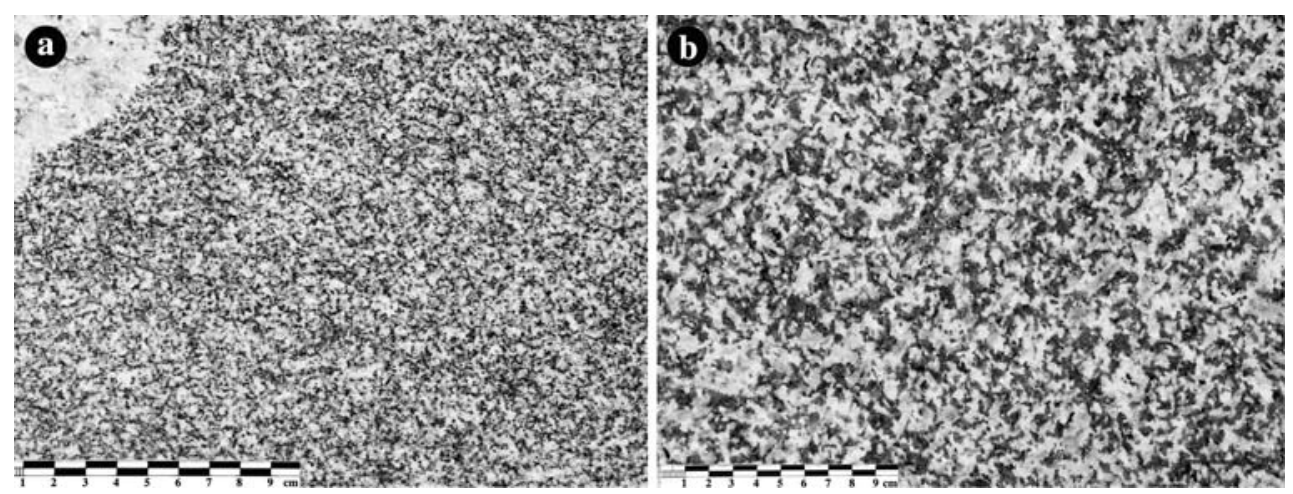

Fig. 2 Macroscopic view of a non-oriented slab of Cezlak granodiorite and $\mathbf{b}$ Flossenbürg granite cut perpendicular to foliation [view to ( $y z$ )plane]. Both slabs have polished surfaces

Fig. 3 Cezlak granodiorite: crystallographic preferred orientation of the a quartz and $\mathbf{b}$ biotite phase: quartz $c$-axis and biotite-(001)-planes, measured by $U$-stage in three oriented thin sections perpendicular to each other

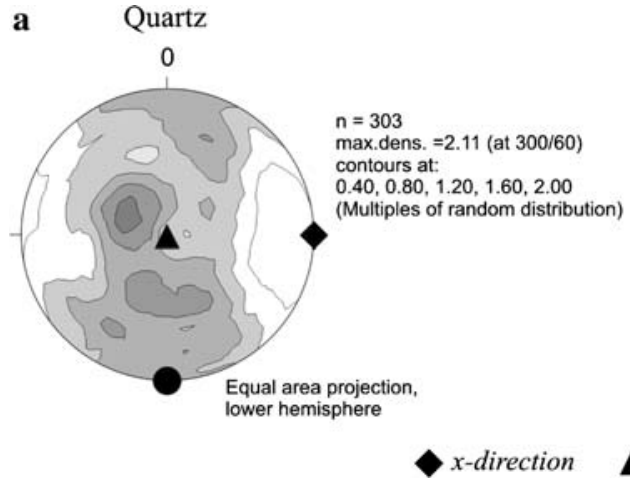

b

b Biotite

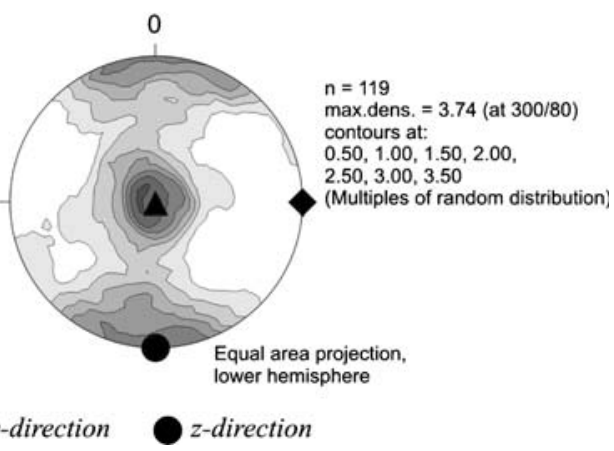

Flossenbürg granite

In comparison to the Cezlak granodiorite, the Flossenbürg granite differs significantly in grain size and the shape fabrics. The macroscopic fabric is characterized by a more or less equigranular medium to coarse grained matrix containing some larger aggregates of feldspar and quartz in sizes up to a few centimeters. Feldspar could also appear as hypidiomorphic to idiomorphic phenocrysts. The modal composition is (vol.\%): quartz 37.5, K-feldspar 20.6, plagioclase 26.9, biotite 2.1, muscovite 4.5, and accessories 0.1 (Vollbrecht et al. 1991). A macroscopic visible foliation cannot be observed. The joint distribution shows a fundamental system (Kendall and Briggs 1933), which is characterized by two joint sets normal to each other.

Microscopically the K-feldspar, which occurs as microcline perthite or banded perthite, often shows a multiple zoning. The plagioclase as well as the K-feldspar is affected by a strong sericitization. Quartz crystals are mainly characterized by irregular lobate grain boundaries and show only rarely deformation features such as deformation bands or subgrain rotation. These structures are mainly limited to bigger grains. However, due to a brittle deformation quartz crystals are often characterized by micro cracks with preferred orientation (Vollbrecht et al. 1991). Micas in general appear to be almost undeformed and biotite casually is altered to chlorite. Further petrographic details are published by Fischer (1965) and Richter and Stettner (1979).

\section{Experimental}

Rock fabrics and bowing potential

For evaluation of the bowing potential of the two different granites bowing tests according to Nordtest Method NT BUILD 499 (2002) were accomplished. Thus, it is possible, to simulate climatic relations or rather variations in an extreme way and to ascertain the damage of the material. In general sample size has been $400 \times 100 \mathrm{~mm}$. Two different thicknesses (15 and $30 \mathrm{~mm}$ ) were used in the case of the Cezlak granodiorite while for the bowing test of the Flossenbürg granite only panels of $15 \mathrm{~mm}$ thickness were used.

The samples were placed in a water film of about $5 \mathrm{~mm}$ (Fig. 4). During the first test series the samples were heated from above (distance about $5 \mathrm{~cm}$ ) up to about $80^{\circ} \mathrm{C}$ (Fig. 4a, left side). The heating takes $6 \mathrm{~h}$ with a subsequent cooling to room temperature over a period of $18 \mathrm{~h}$. In a second test series with a slightly different experiment setup (here the samples were placed in a water-saturated bed 

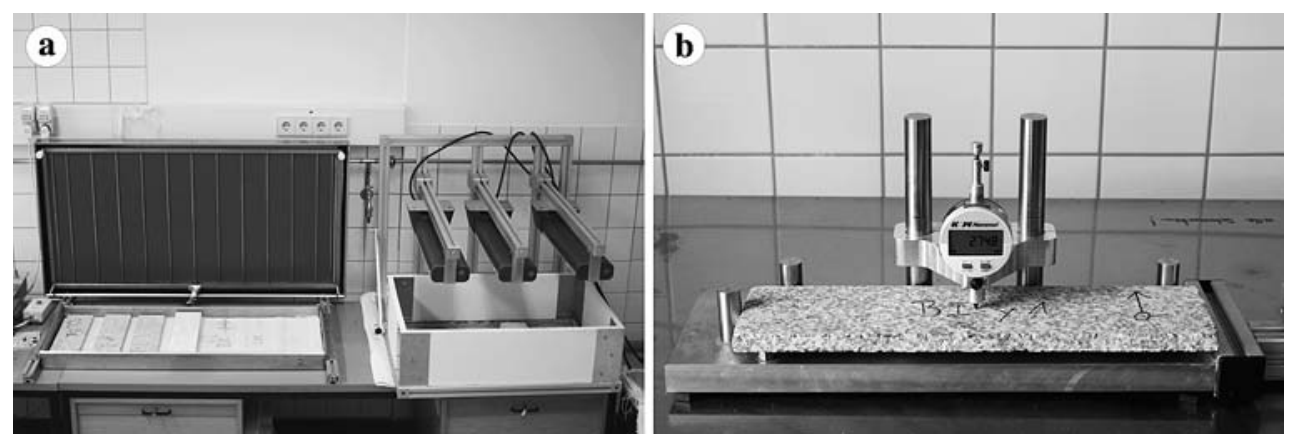

Fig. 4 a Experiment set-up for the first (left side) and the second (right side) test series. b Measurement bridge for evaluation of the effective bowing

of grit, distance to heating system about $50 \mathrm{~cm}$, Fig. $4 \mathrm{a}$, right side) the maximum temperature was set to $120^{\circ} \mathrm{C}$, whereas the sequence of heating and cooling were the same. In contrast to the sample set FG, a second sample set was used for bowing test with higher destination temperature in the case of Cezlak granodiorite. The total number of heating/cooling cycles was 50 for the Cezlak granodiorite and 40 for the Flossenbürg granite.

The bowing has been measured after each three cycles by using a measurement bridge (accuracy: $\pm 1 \mu \mathrm{m} / 35 \mathrm{~cm}$; Fig. 4b). For zero position a core of silica glass in length of 15 and $30 \mathrm{~mm}$, respectively, with coplanar front surfaces was used. The translation of bowing data to $\mathrm{mm} / \mathrm{m}$ was based upon the circle equation of Koch and Siegesmund (2004). Positive values are associated with convex bowing, while negative values indicate concave bowing.

The bowing tests were carried out on slabs cut in various directions with respect to the rock fabrics. For the Slovenian granodiorite (sample set SLO) the samples were oriented with respect to the macroscopic fabrics like the foliation (the normal to the foliation plane is the $[z]$-axis, Fig. 5). Since the available block size was limited only two different directions of the slabs for the bowing tests could be prepared. The samples $\mathrm{C}$ and $\mathrm{C}^{\prime}$ originate from different planes each oriented parallel to $[z]$-axis.

Due to the lack of any macroscopic visible fabrics in the case of the Flossenbürg granite (samples FG) a different coordinate system was introduced. The samples for the bowing tests were cut according to selected maxima of joints and microcracks (Fig. 6a, c) as reported by Vollbrecht et al. (1991). In addition, a second sample set was prepared with respect to the joint pattern observed in the quarry (Fig. 6b). In this case the dip direction seems to be rotated at about $45^{\circ}$ to these of Vollbrecht et al. (1991).

\section{Neutron diffraction residual strain measurement}

The possibility to measure intra-crystalline residual strain in rocks is based on the crystalline properties of the material. Diffraction methods, like X-ray or neutrons uses the properties, so that the determination of lattice spacing is given by fulfilling the Bragg's law

$2 d \sin \Theta=n \lambda$

with $d$ being lattice spacing, $\Theta$ diffraction angle and $\lambda$ wavelength). The Bragg diffraction line corresponds to
Fig. 5 a Definition of coordinate system of sample set SLO (Cezlak granodiorite). The (xy)-plane describes the foliation. All subsequent pole figures concerning sample set SLO are rotated to the view to the $(x z)$-plane (perpendicular to the foliation and parallel to the $[x]$-axis). b Appellation of samples; the lack of sample with its long axis parallel to $[y]$-axis is due to dimensions of the available sample block
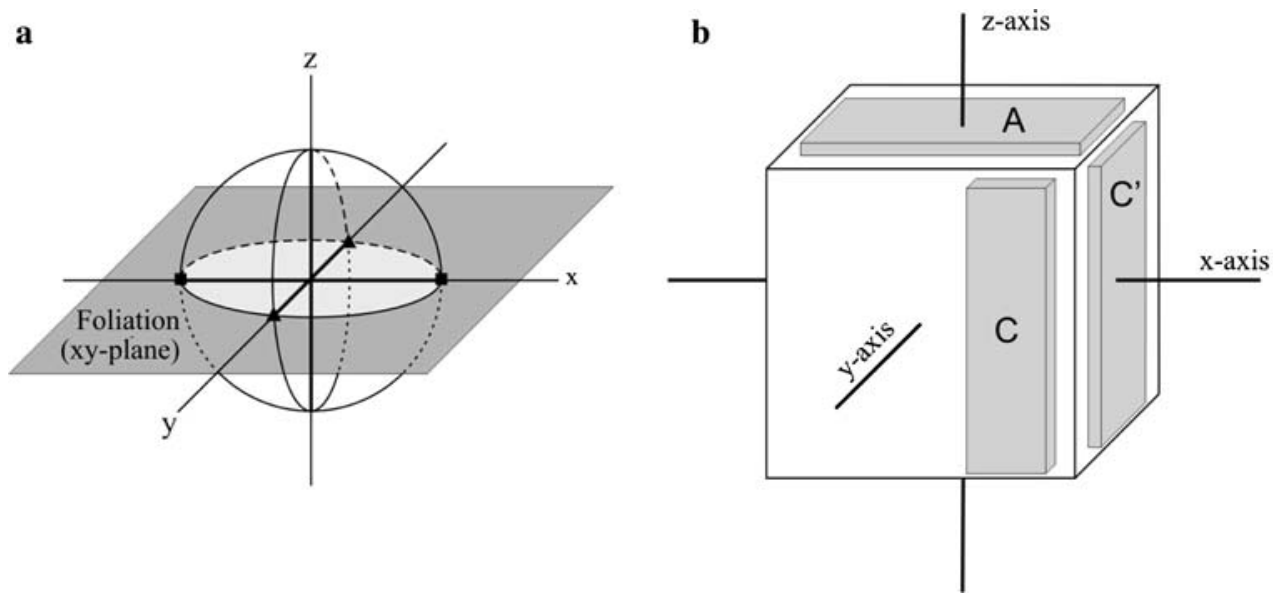
Fig. 6 Basis for the definition of coordinate system for sample set FG (Flossenbürg granite). Pole figures of a joint distribution and $\mathbf{c}$ microcrack distribution after background of Vollbrecht et al. (1991) for sample set FG BII. b Pole figure of local joint distribution as basis for sample block FG BI. d Appellation of samples
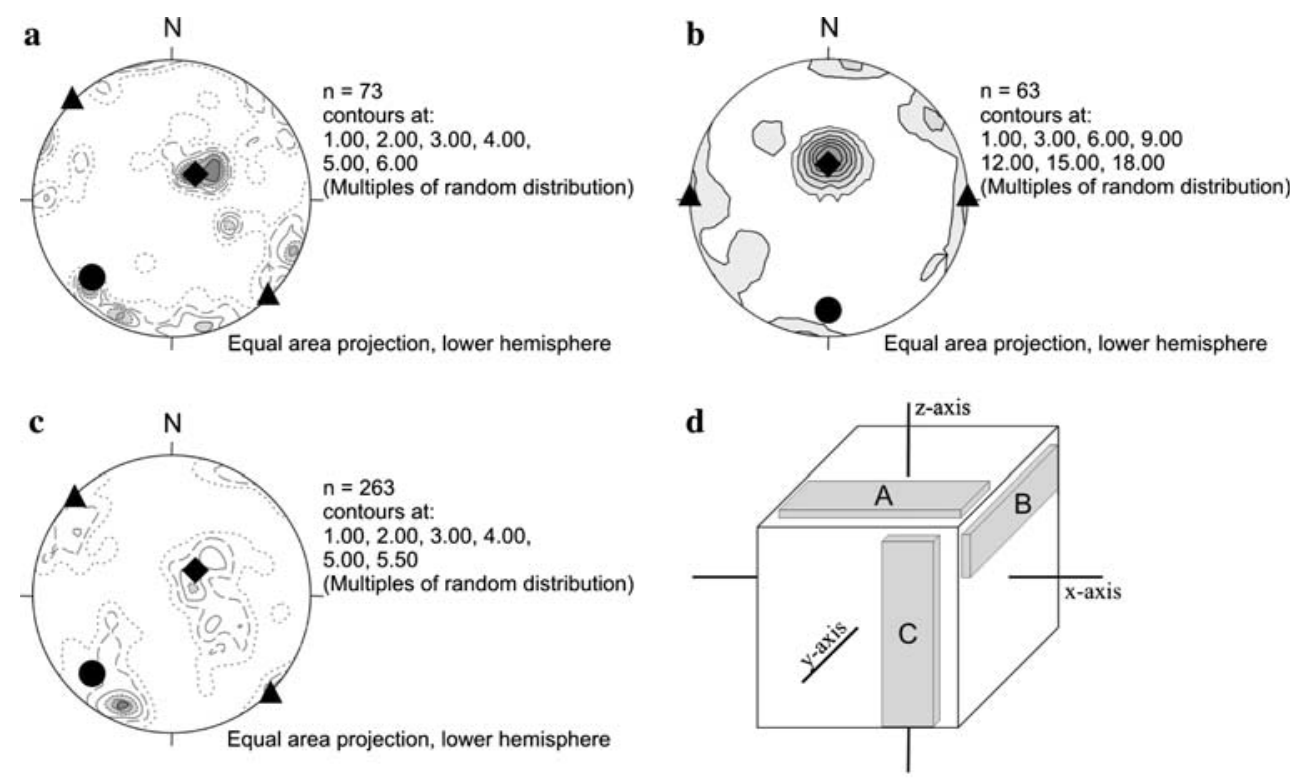

$\left.\begin{array}{c}x \text {-direction } \\ y \text {-direction } \\ z \text {-direction }\end{array}\right\}$ Orientation of samples

their Miller indices. In comparison to X-ray, the penetration depth of neutrons allows investigating bulk material with dimensions in cm-range by Bragg diffraction. A high resolution diffraction method is required to investigate rock materials consisting of more than one mineral phase and minerals with lower crystal symmetry, because of the Bragg line density in the diffraction pattern. The application of high resolution neutron time-of-flight diffraction enables to detect all Bragg lines of the minerals in the characteristic wavelength-range, so that this method is very suitable to investigate geological material.

The diffractometer EPSILON-MDS for strain/stress analysis (Walther et al. 2005) at the fast pulsed research reactor IBR-2 in Dubna offers to investigate crystalline materials with lattice spacing up to $d=5.5 \AA$ at high resolution, as required for our study. The diffractometer uses diffraction geometry of $2 \Theta=90^{\circ}$ and it is equipped with nine radial collimators, and each of the collimator is operated with nine detectors. Combining the signals of the nine individual detectors using time focusing method (Walther et al. 2005), nine sample directions on the DebyeScherrer-cone can be detected simultaneously. The timeanalyzer channel width is $32 \mu$ s to achieve a high resolution. In the incident beam a beam slit system is installed to investigate small sample volumes and to carry out strain scans with small gauge volumes.

A diffraction pattern of the Cezlak granodiorite is shown with the corresponding lattice spacing and the indication of the Bragg reflections of quartz and feldspars (Fig. 7).

The background of the Bragg diffraction peaks has been approximated by linear relation; the asymmetrical peak shape has been fitted by an asymmetrical Gaussian function (Scheffzük et al. 2007).

\section{Results}

Results of bowing experiments

Samples of the Cezlak granodiorite with two different thicknesses were tested with respect to their bowing potential. First, 25 cycles with a maximal temperature of

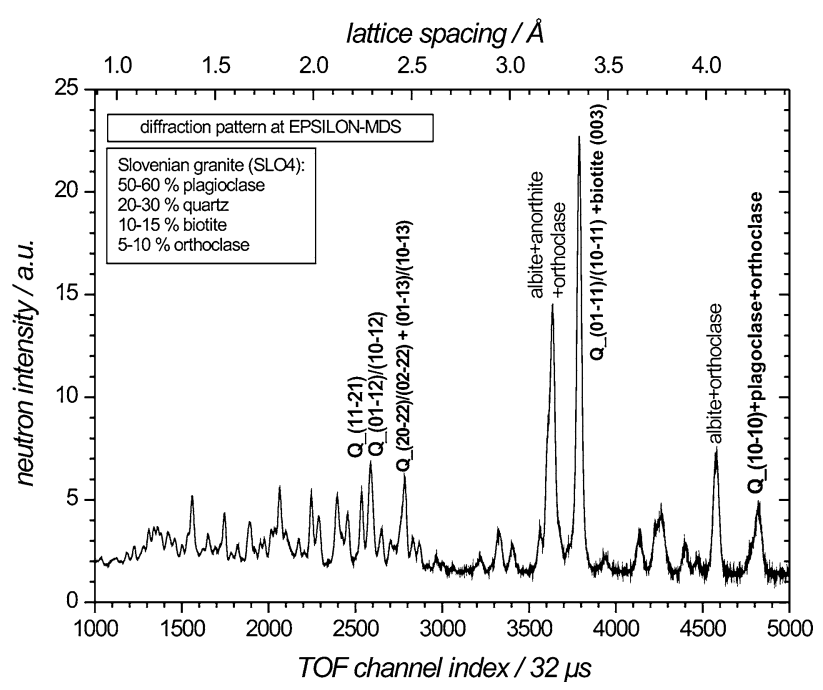

Fig. 7 Neutron time-of-flight diffraction pattern of the Cezlak granodiorite 
Fig. 8 Cezlak granodiorite. Bowing of panels as function of counter thickness and induced temperature. Starting temperature of each cycle was approximately $20^{\circ} \mathrm{C}$. The interdependence of panel thickness and the effect of rock texture becomes apparent
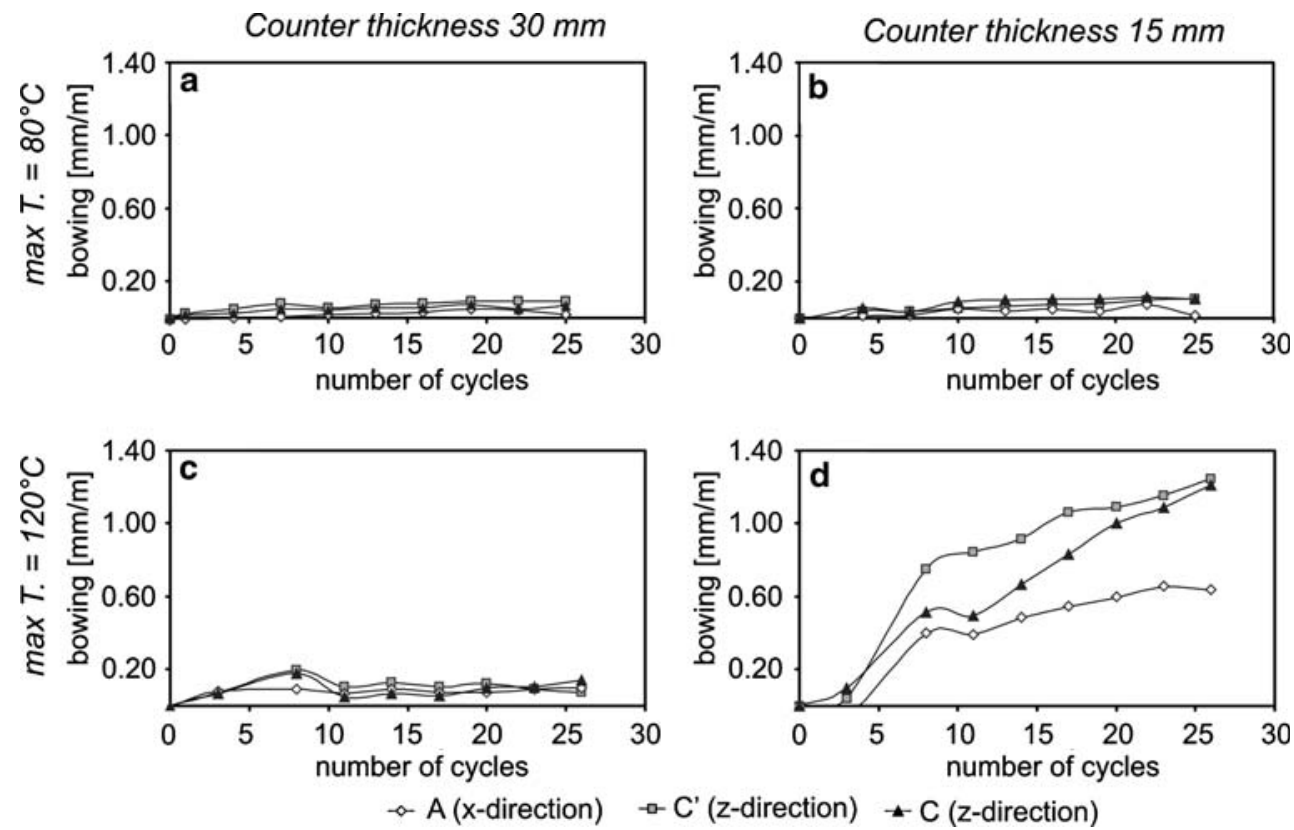

$80^{\circ} \mathrm{C}$ were carried out, where no clear bowing could be observed (Fig. 8a, b). A maximal value of $0.106 \mathrm{~mm} / \mathrm{m}$ was obtained for the $15 \mathrm{~mm}$ thick samples of $\mathrm{C}$ and $\mathrm{C}^{\prime}$ (both parallel to the [z]-axis, see Fig. 5). With increasing temperature up to $120^{\circ} \mathrm{C}$ a significant bowing of the samples can be observed, but exclusively for the slabs with thickness of $15 \mathrm{~mm}$ (Fig. 8c, d). Here the maximal values were determined for the samples $\mathrm{C}$ and $\mathrm{C}^{\prime}$ too, varying between 1.206 and $1.249 \mathrm{~mm} / \mathrm{m}$, respectively, while for

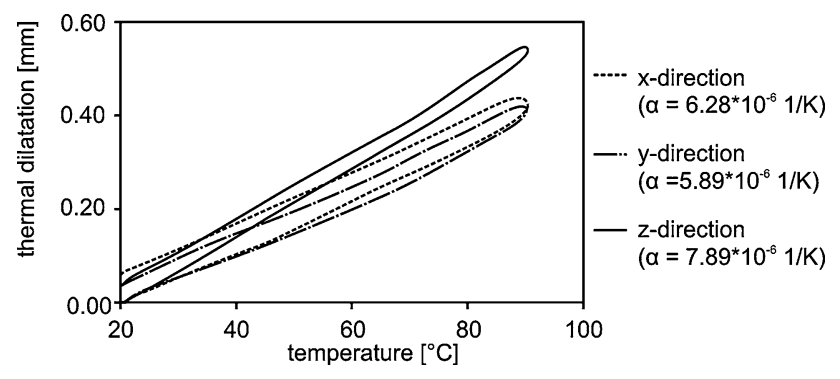

Fig. 9 Cezlak granodiorite: experimentally determined thermal dilatation as a function of temperature the sample sets of $30 \mathrm{~mm}$ thickness any bowing is lacking. Additionally investigations of the thermal expansion behaviour of the Cezlak granodiorite have shown, that the thermal expansion coefficient $\alpha$ reaches its maximum parallel to the $[z]$-axis (Fig. 9), which correlates with the results of bowing anisotropy.

For the Flossenbürg granite the results of the bowing tests are generally comparable (Fig. 10). The local joint system used as the reference system for sample set FG BI (see Fig. 6b), is of minor importance for the bowing behaviour, therefore the following discussion is focused on FG BII. In contrast to the Cezlak granodiorite a weak bowing can be observed even at the lower destination temperature up to $80^{\circ} \mathrm{C}$. The experiments performed at higher temperatures causes a pronounced bowing (Fig. 10). Maximum values of up to $3.984 \mathrm{~mm} / \mathrm{m}$ (sample FG BII-A, parallel to $[x]$ direction) and $3.935 \mathrm{~mm} / \mathrm{m}$ (sample FG BII-B, parallel [y]direction) can be observed. Remarkably, the maximal data for a marble, which was heated in the same cycles for comparison, are only insignificantly higher. Even the slightest bowing of $2.955 \mathrm{~mm} / \mathrm{m}$ (sample FG BII-C, parallel
Fig. 10 Flossenbürg granite. Starting temperature of each cycle was approximately $20^{\circ} \mathrm{C}$. The local joint system, as reference system for sample set FG BI (cp. Fig. 6b), has a lower effect to the bowing potential

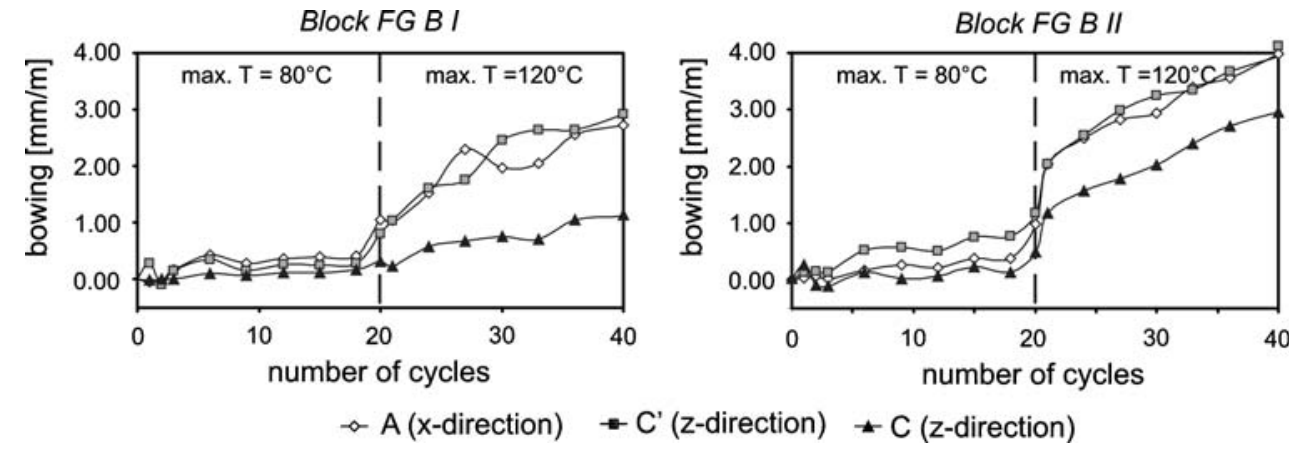




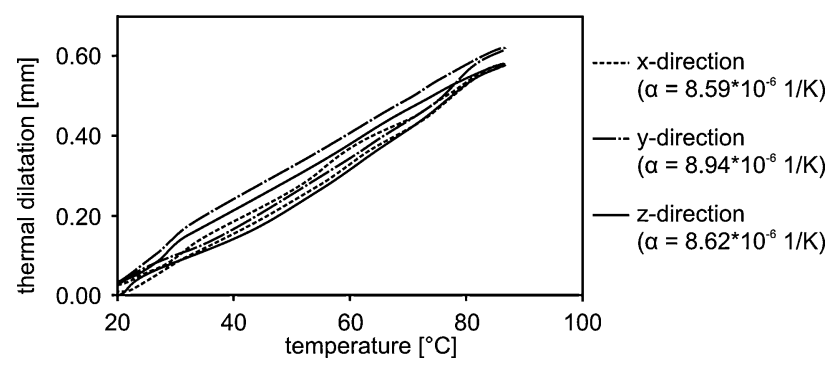

Fig. 11 Flossenbürg granite: experimentally determined thermal dilatation as a function of temperature

[z]-axis) exceeds more than twice the maximum value for the Cezlak granodiorite. The accompanying analysis of thermal dilatation shows only a weak anisotropy (Fig. 11), which is not reflected in the results of the bowing experiment. Here, sample C (parallel to [z]-axis, i.e. perpendicular to the foliation plane $(x y))$ shows distinctly lower bowing.

However, both varieties show a more or less extensive bowing, whereas the Flossenbürg granite gives the highest absolute values so far. As assumed due to the macroscopic visible foliation, the differences in bowing behaviour related to sample orientation is more pronounced for the Cezlak granodiorite. Furthermore, it is to observe that the samples of both the investigated granitoids exhibit a slight residual strain after cooling down to room temperature, equivalent with a thermal degradation of the rocks (Koch and Siegesmund 2004).

\section{Residual strain data}

A strain scan has been performed at the strain diffractometer EPSILON-MDS by moving the sample SLO2 (Cezlak granodiorite) into the foliation plane (xy), parallel to $[x]$-direction, such that seven positions could be measured with a step width of $10 \mathrm{~mm}$. The Bragg diffraction lines $(10-11) /(01-11)$ and $(01-12) /(10-12)$ of quartz were used for the strain analysis, because the other Bragg diffraction lines are superimposed by diffraction lines of muscovite and biotite. The observed strain data shows a homogeneous strain field relating the strain scan across the $[x]$-axis (Fig. 12a-c).

The quartz-(10-11)/(01-11) Bragg diffraction line is characterized by positive strain values (extension) up to about $0.59 \times 10^{-3}$ at all scan positions, whereas the $[y]$ direction of the sample demonstrates negative strain values (compression state) with a strain average value of $-0.19 \times 10^{-3}$ (Fig. 12a).

The strain data of quartz (01-12)/(10-12) in [y]-direction are very stable and show compression state. The data varies only in the range of $-0.37 \times 10^{-3}$ and $-0.75 \times 10^{-3}$, whereas the $[x]$-direction shows a much stronger compression state with some fluctuations in the range of $-0.88 \times 10^{-3}$ and $-1.7 \times 10^{-3}$ (Fig. 12b).
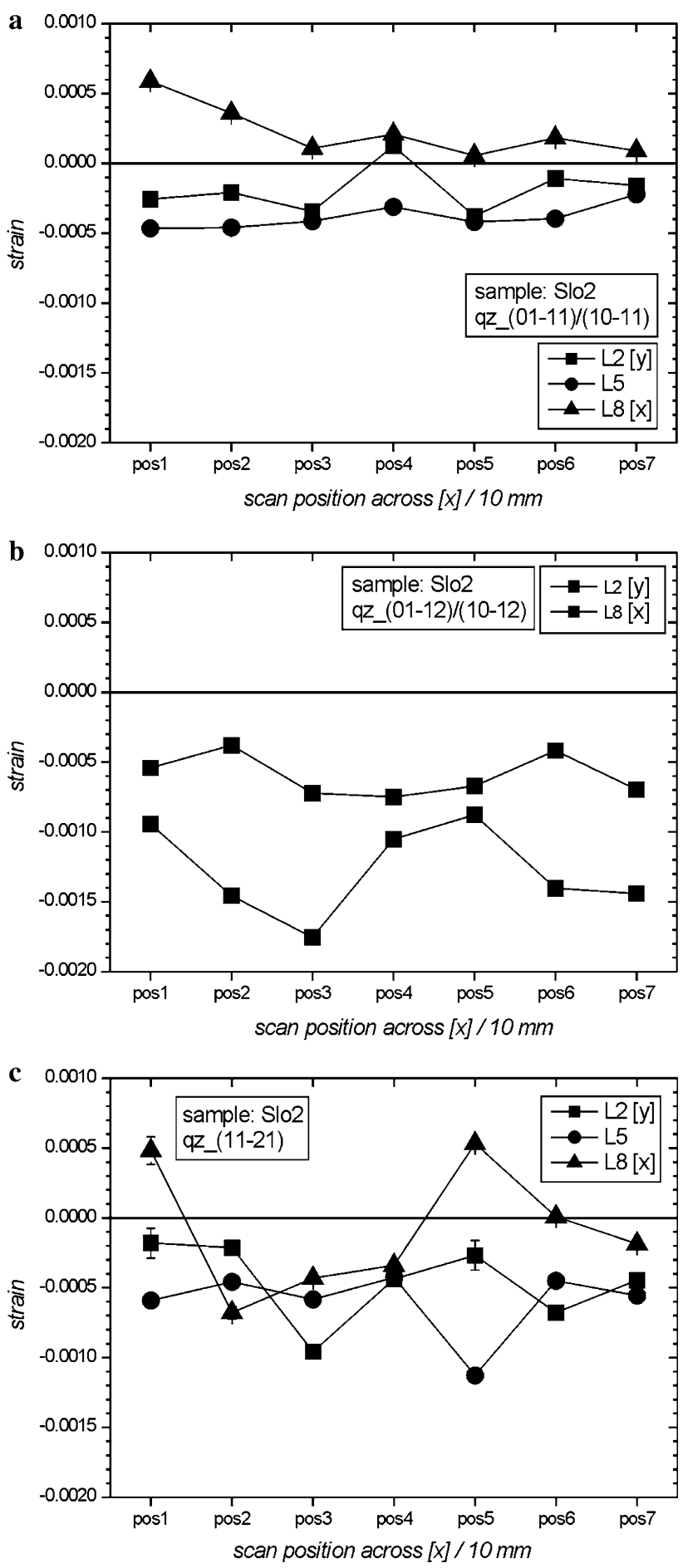

Fig. 12 Granodiorite from Cezlak (Slovenia); sample SLO2: Residual strain of some quartz-Bragg reflections, determined by neutron diffraction: a q-(10-11)/(01-11), b q-(01-12)/(10-12), and c q-(1121). L2, L5, and L8 are related to the instrument and indicate different sample directions

The (11-21) lattice plane of the [y]-direction is also under compression up to $9.6 \times 10^{-4}$, the residual strain in $[x]$-direction fluctuate from compression $\left(-0.68 \times 10^{-3}\right)$ 
to extension $\left(0.48 \times 10^{-3}\right)$ across the scan in $[x]$-direction (Fig. 12c).

\section{Discussion and conclusion}

Bowing of marbles is to be considered as coming along with irreversible expansion of the stone forced by the impact of temperature changes and moisture (e.g., Koch and Siegesmund 2004). The thermal expansion behaviour of marbles, the residual strain and its anisotropy, i.e., progressive microcracking, may be easily explained by the texture and single crystal coefficients of calcite (calcite contracts normal to the $c$-axis $\left(\alpha=26 \times 10^{-6} \mathrm{~K}^{-1}\right)$ and expands parallel to the $c$-axis $\left(\alpha=-6 \times 10^{-6} \mathrm{~K}^{-1}\right.$ ) while heating. In the case of granitoids, the thermal expansion is more complex due to the polyphase composition and the rock fabrics. For example, quartz with a crystallography comparable to calcite shows the smallest expansion coefficient parallel to the $c$-axis $\left(\alpha=7.7 \times 10^{-6} \mathrm{~K}^{-1}\right)$ and the highest $\left(\alpha=13.3 \times 10^{-6} \mathrm{~K}^{-1}\right)$ perpendicular to it. For biotite the thermal expansion is $17.3 \times 10^{-6} \mathrm{~K}^{-1}$ parallel to $c$-axis and $9.65 \times 10^{-6} \mathrm{~K}^{-1}$ perpendicular to it. The available data for plagioclase is of less quality. However, the effects of feldspars can be treated as isotropic in the case for the Cezlak and Flossenbürg granitoids.

For the Flossenbürg granite the thermal expansion is more or less isotropic $\left(A=0.03\right.$ with $\left.A=\left(\alpha_{\max }-\alpha_{\min }\right) / \alpha_{\max }\right)$, with values varying between $\alpha=8.94 \times 10^{-6} \mathrm{~K}^{-1}$ and $\alpha=8.59 \times 10^{-6} \mathrm{~K}^{-1}$. In contrast, the Cezlak sample is significantly anisotropic $(A=0.25)$ with respect to its thermal expansion: $\alpha=7.89 \times 10^{-6} \mathrm{~K}^{-1}$ parallel to the [z]-direction [i.e. normal to the foliation plane $(x y)$ ] and $\alpha=5.89 \times 10^{-6} \mathrm{~K}^{-1}$ parallel to the [y]-direction. In the case of the Cezlak granodiorite the directional dependence of the thermal expansion may be explained by a model of idealized parallel layers with the number and thickness of each individual layer related to the rock-forming minerals and their volume fraction. These relationships correspond to the averaging procedures of Voigt and Reuss in the case of the thermal expansion parallel and perpendicular to the layer boundaries, respectively.

In order to get an estimate of the extent to which each mineral contributes to the measured anisotropy of the thermal expansion, a comparison is made between the texture and the computed texture-based thermal expansion for a monomineralic aggregate. The quartz induced thermal expansion pattern of sample SLO (Fig. 13a) exhibits the $\alpha_{\max }$-value parallel to the $[x]$-direction while $\alpha_{\min }$ should be oriented parallel to the $c$-axis maximum, i.e., subparallel to the $[y]$-direction. However, the quartz $c$-axis texture is weak, consequently the calculated thermal expansion varies between $10.8 \times 10^{-6}$ and $11.8 \times 10^{-6} \mathrm{~K}^{-1}$. The poles of biotite (001)-cleavage planes (Fig. 3b) show a distinct girdle pattern around the $[x]$-direction with two distinct submaxima: one is oriented parallel to the $[y]$-direction within the foliation and the second one is subparallel to the foliation pole. The texture-derived $\alpha$-stereogram (Fig. 13b) shows the $\alpha_{\text {max }}$-value parallel to the broad maximum in the center of the pole figure. The minimum is oriented more or less parallel to the $[x]$-direction. From these results it could be concluded that the preferred orientation of biotite and the weak texture of quartz mainly cause the measured anisotropy of the thermal expansion. The contribution of the feldspar fraction is assumed to be isotropic. The combined effects of quartz and biotite should produce the lowest thermal expansion parallel to the $[z]$-direction, i.e., perpendicular to the foliation plane $(x y)$. However, the influence of quartz-texture (Fig. 3a) should be of minor importance because the modelled texture-based $\alpha_{\max }$ (Fig. 13a) is parallel to the $[x]$-direction corresponding to the direction of the lowest bowing (Fig. 8).

In the case of the Flossenbürg sample a more or less random orientation of the major rock-forming minerals is obvious because any macroscopic fabric is missing. Consequently, the thermal expansion behaviour (Fig. 11) is more or less isotropic. However, both granitoids clearly show bowing in dependence on temperature and the degree of moisture, as well as thickness of the slabs. The investigation of the porosity and the effective pore radii
Fig. 13 Cezlak granodiorite: averaging thermal expansion of a quartz and $\mathbf{b}$ biotite calculated from their respective texture (cp. Fig. 2)
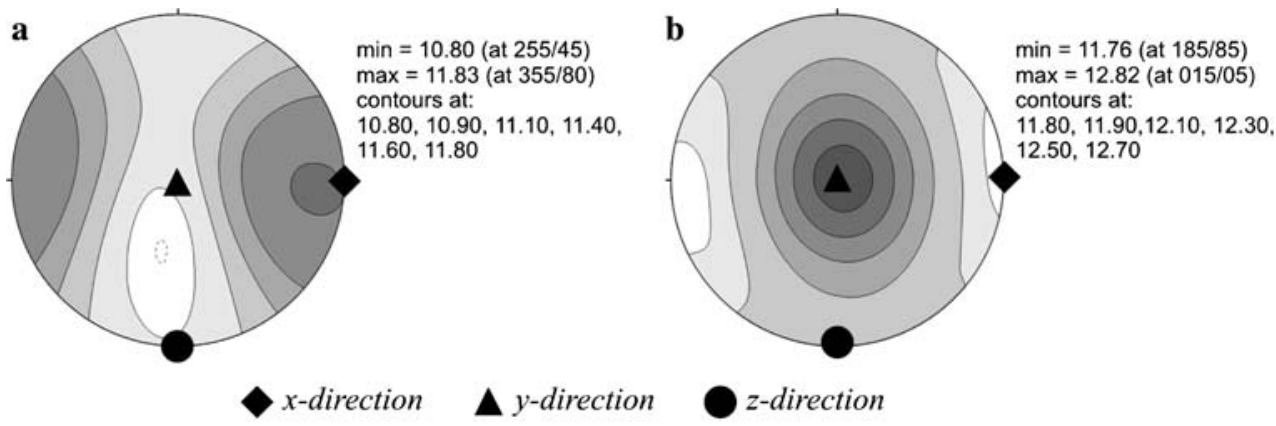
Fig. 14 Distribution of effective pore radii of fresh and bowed samples (related to destination temperature of $120^{\circ} \mathrm{C}$ ) determined by $\mathrm{Hg}$ porosimetry. Included in each diagram are the total effective porosity [vol.\%] and the $p$-wave velocity $[\mathrm{km} / \mathrm{s}]$
Fresh sample
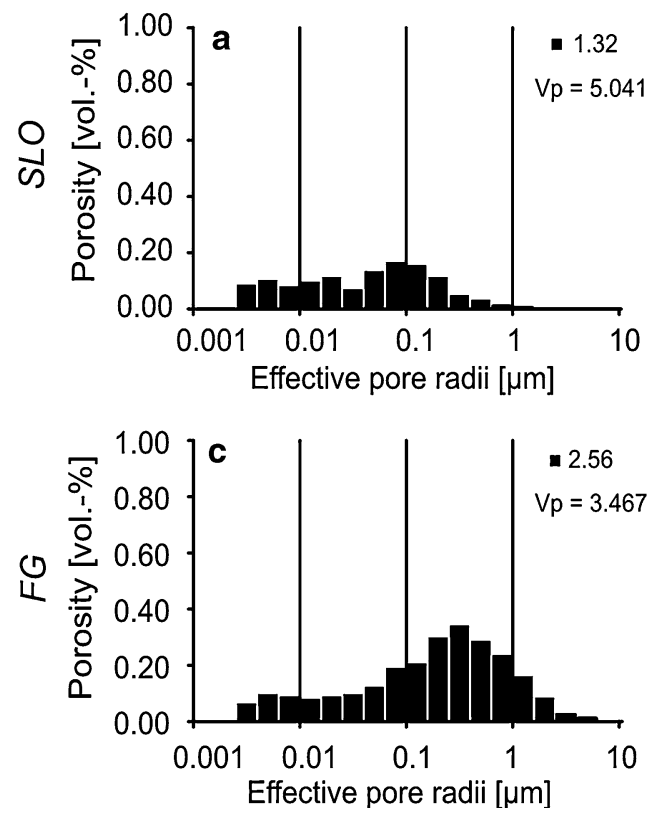

Bowed sample
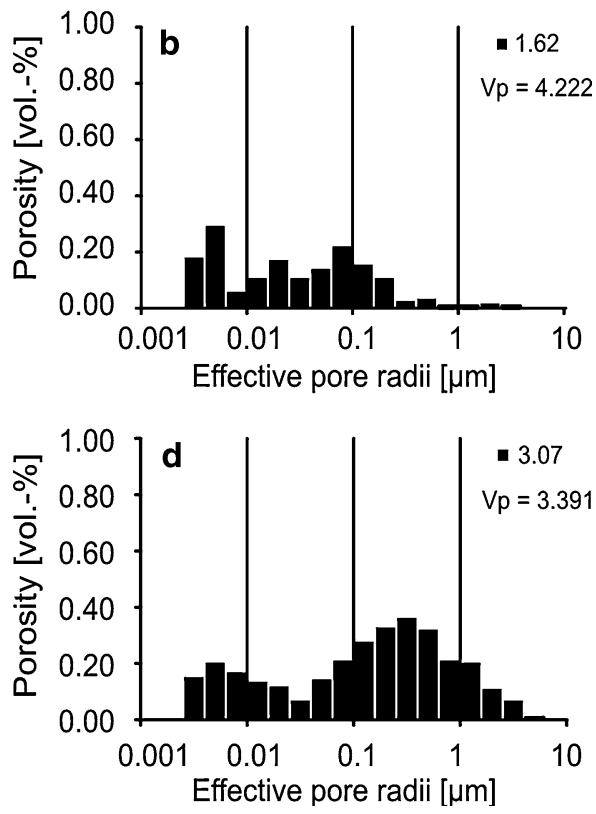

(Fig. 14) clearly demonstrates that both parameters changed due to the thermal treatment. After 25 bow test cycles with destination temperatures of $80^{\circ} \mathrm{C}$ the pore space increase is less pronounced, while after 25 cycles up to $120^{\circ} \mathrm{C}$ a significant change occurred. The porosity increases up to $23 \%$ mainly induced by a larger amount of new micropores whereas only a slight shift to larger pores is observed. Following the theoretical quartz-feldspar-model of Vollbrecht et al. (1991) a closing of microcracks in quartz should to be expected primarily while heating. However, to explain the bowing as a result of a change in volume, the opening of existing cracks, the reopening of healed cracks or the generation of new cracks is very likely. Besides this the increase of porosity is also reflected in the comparison of the acquired values for the $P$ wave velocities of fresh and bowed samples (Fig. 14).

The first topic to be discussed in terms of bowing is the thermal stress that results from differential thermal expansion between different coexisting minerals or between the same minerals of different crystallographic orientation. The volume expansion of quartz and mica is about four times higher than that of feldspars [in $10^{-6} \mathrm{~K}^{-1}$ ]: 37.0 quartz, 35.4 muscovite, 12.6-15.8 K-feldspar, 10.4-14.0 plagioclase and 6.59 albite (data from Strohmeyer 2003 and Fei 1995). This contrast may cause excessive internal stresses during moderate heating, at least leading to microcracking. In the case of quartz-quartz grain boundaries a closure of open cracks or the initiation of new microcracks is significantly controlled by their misorientation. Primary closing of remaining open cracks could result in new microcracking as a consequence of constricted extension movement of single crystals. Phase boundaries between quartz and mica and also between quartz and feldspar may cause a progressive microcracking. In the case of muscovite and biotite the volume expansion may result in an opening of the (001)-mica cleavage planes. Furthermore, the opening of mica flakes can be enforced by thermal expansion of neighboured quartz crystals, especially if the quartz-c-axis is oriented parallel to the $c$-axis of the mica. Microscopic observations of Flossenbürg granite give evidence of the penetrative fragmentation of feldspar crystals. In an advanced model based on the two component system of Vollbrecht et al. (1991), the quartz cores surrounded by a feldspar mantle may cause brittle deformation of the feldspar component.

The bowing of granite samples is discussed as continuous process. Mauko et al. (2006) investigated removed façade panels from a 34 year old building in Ljubljana, which were characterized by penetrative bowing. For these slabs a clear tendency to an increased bowing of already deteriorated panels could be detected for heating cycles up to $80^{\circ} \mathrm{C}$ only. Microscopical studies give evidence that the reactivation of healed cracks and the generation of new cracks could be associated with the thermal treatment. Interestingly, the same micro crack features are observable in the both varieties, Flossenbürg granite as well as Cezlak granodiorite (Fig. 15).

Logan (2004) carried out cyclic heating-cooling experiments on marble and concluded that residual stress contributes to a loss of strength in marble, but more importantly is a critical factor for the bowing. Scheffzük et al. (2007) found from thermal expansion data, together 
Fig. 15 Characteristics of microcracks in the investigated granitoids. Cezlak granodiorite: a multiple fluid inclusion trails, the partly dark appearance of the aligned fluid inclusions could be due to a reopening of healed cracks; $\mathbf{b}$ healed transgranular cracks in quartz with typical ladder-shaped pattern; c shorter healed crack with fluid inclusions crosscut by a microcrack which is apparently partial opened (arrows). Flossenbürg granite: d weak chessboard pattern in quartz with more or less orthogonal pattern of fluid inclusion trails; e brittle deformation of quartz crystals with irregular crack pattern; $\mathbf{f}$ overlapping of open (horizontal) and healed crack (trail of fluid inclusions)
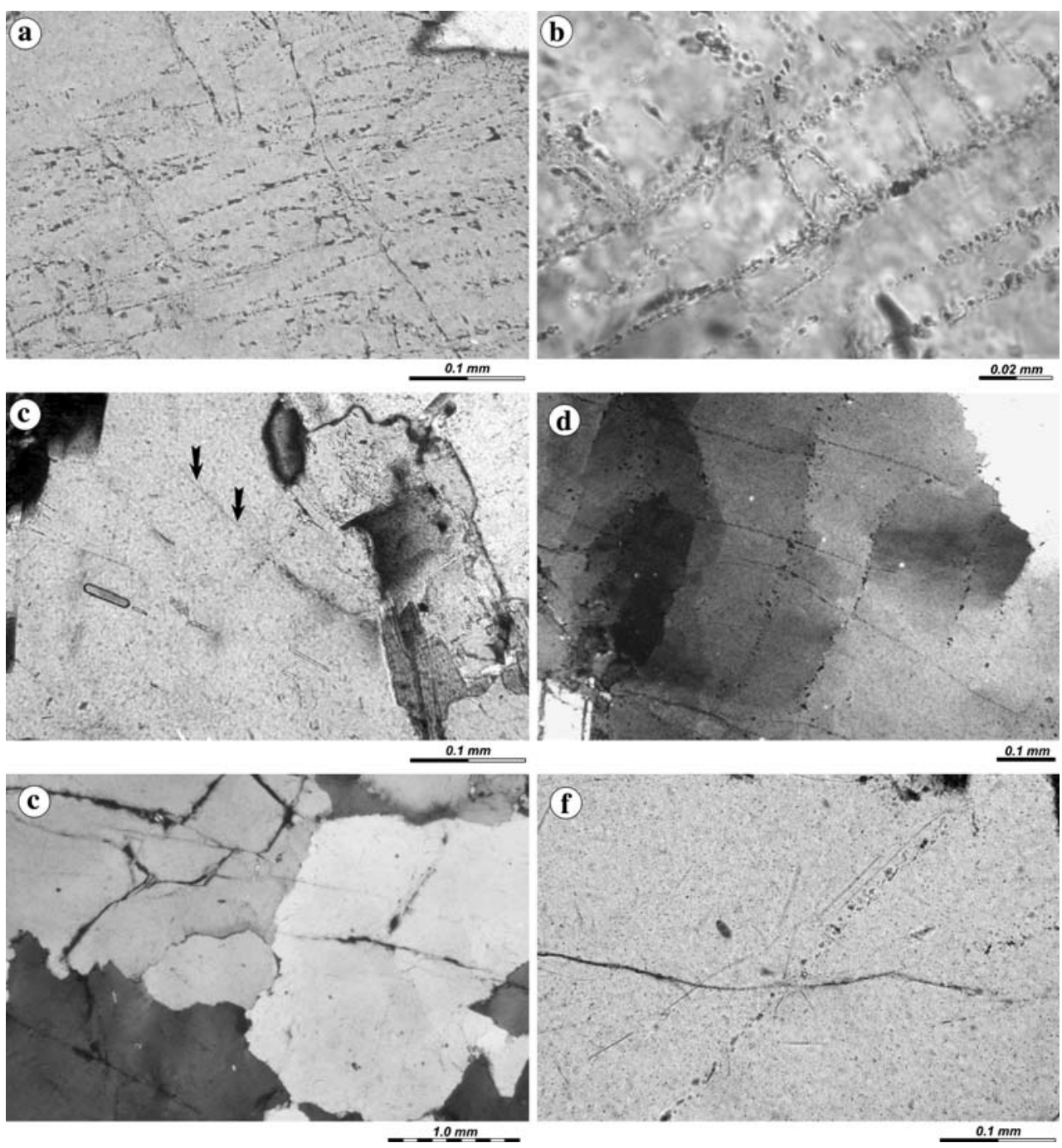

with the observed different intensities of bowing in comparison with neutron diffraction data of residual strain that the so-called locked-in stress should have an important impact on the bowing of marbles. Since residual strain investigation is very limited, there is a lack of data on how it is in granite. Nichols (1975) and Wolter (1987) analyzed the locked-in stress with the over-coring method. Nichols (1975) obtained extension strain of $0.33 \times 10^{-3}$ and compressional strain of $-0.27 \times 10^{-3}$, whereas Wolter (1987) obtained much lower strain values by the overcoring method of about $32 \mu \mathrm{m} / \mathrm{m}$ (corresponding to $\left.0.03 \times 10^{-3}\right)$. In the case of the investigated granitoids residual strain values were detected by neutron diffraction, ranging from $-1.7 \times 10^{-3}$ (compression) to $0.59 \times 10^{-3}$ (expansion). Friedman (1972) reported about quartz residual strain magnitudes in different granites up to $0.25 \times 10^{-3}$, equivalent to a stress of about $20 \mathrm{MPa}$, measured by X-ray diffraction technique.

$\mathrm{X}$-rays can penetrate into bulk material only up to $100 \mu \mathrm{m}$. Thus, X-rays are suitable to detect surface strain with high resolution, but they are limited to detect the higher volumetric strain in bulk materials. Taking into account, that the strain in the surface does not reflect the volumetric strain, the strain magnitudes, determined by X-ray and neutron diffraction are similar. Similar strain values were reported by Reik (1976), who calculated differential stresses of 10-30 MPa from X-ray data, whereas the measured stress values are $30-40 \mathrm{MPa}$. Time-of-flight neutron diffraction experiments have been applied to investigate the residual strain of a granite sample after a deformation with a load of $95 \mathrm{MPa}$ (Frischbutter et al. 2006). Using the strain scanning method across a cylindrical sample residual strain values from $-1.3 \times 10^{-3}$ to $0.7 \times 10^{-3}$ has been detected.

Savage (1978) and Vollbrecht et al. (1991) found that residual stresses in granitoids may be caused by thermal stresses resulting from different thermal contraction of quartz aggregates compared to the surrounding feldspar/ mica framework during cooling and uplift. Savage (1978) considered the granitic pluton as a special inclusion within 
the infinite country rock, because cooling leads to different elastic strains since radial and tangential stresses are evident. Consequently, the superposition of two stress states, tectonic and thermal, occurs during cooling and solidification. Thermoelastic stresses can significantly exceed tectonic stresses. According to Timoshenko and Goodier (1970), the maximum horizontal thermoelastic stress $\left(\sigma_{\mathrm{T}}\right)$ can be calculated by:

$\sigma_{T}=\Delta T /(1-v)$

where $\alpha$ is the thermal expansion coefficient, $E$ is the Young's modulus, $\Delta T$ is the temperature difference and $v$ is the Poisson's ratio. Assuming a cooling rate of $100 \mathrm{~K}$ the thermoelastic stress is about $-21.3 \mathrm{MPa}\left(\alpha=8 \times 10^{-6}\right.$ $\mathrm{K}^{-1}, E=20 \mathrm{GPa}, v=0.25$ ). Precise expression of the experimentally measured residual strains as stresses is difficult, because the distribution and magnitudes of locking and locked-in stress is not known. The threedimensional strain distribution and the textural properties determine the strain-stress relation. But for the isotropic case an approximation of the locked-in stresses can be given as a rough estimate for the investigated Cezlak and Flossenbürg. Taking into account the Hooke's law the approximated locked-in stresses can be given with about 50-140 MPa.

In contrast to the observations discussed above, Winkler (1996) discussed the action of moisture triggered expansion based on the observation on the bowing of granite tombstones at the Greenwood cemetery. However, it seems that the thermal properties of the rock-forming minerals, especially its contracting thermal properties of quartz, biotite and feldspar minerals may control the bowing. The environmental conditions (i.e., temperature and moisture) are of critical importance. Preliminary data on the lockedin-stress may also have an influence on the bowing.

However, it is a fact that the combined effect of moisture and temperature may lead to extensive bowing of granitoids, as it is known for marbles or limestones. Thereby a crystal preferred orientation causes an increasing anisotropic behaviour but it has only a minor effect to the intensity of bowing. The thermal degradation of granitic rocks is probably based on the interaction between the involved mineral phases and there specific thermal behaviour, leading to microcracking or the regeneration of healed cracks, respectively. If water is present, the bowing of the rock is to regard as a progressive process, which was obtained from the laboratory bow tests.

Acknowledgments The work was supported through the BMBF grants 03-DU03X4 and 03-DU03G1. We thank the Granitwerke Baumann GmbH, Flossenbürg, and the MABRA inženiring d.o.o., Ljubljana, for providing the samples. The reviewers J. Logan and $\mathrm{K}$. Ullemeyer are gratefully acknowledged.

\section{References}

Battaglia S, Franzini M, Mango F (1993) High sensitivity apparatus for measuring linear thermal expansion: preliminary results on the response of marbles. Il Nuovo Cimento 16:453-461

Fei Y (1995) Thermal expansion. In: Ahrens TJ (ed) Mineral physics and crystallography - a handbook of physical constants 2 . American Geophysical Union, Washington, p 354

Fischer G (1965) Über die modale Zusammensetzung der Eruptiva im ostbayrischen Kristallin. Geol Bavaria 55:7-33

Friedman M (1972) Residual elastic strain in rocks. Tectonophysics 15:297-330

Frischbutter A, Janssen Ch, Scheffzük Ch, Walther K, Ullemeyer K, Behrmann JH, Nikitin AN, Ivankina TI, Kern H, Leiss B (2006) Strain and texture measurements on geological samples using neutron diffraction at IBR-2, Joint Institute for Nuclear Research Dubna (Russia). Phys Part Nucl 37(Suppl. 1):S45-S68

Grimm WD (1999) Beobachtungen und Überlegungen zur Verformung von Marmorobjekten durch Gefügeauflockerung. Zeitschrift Deutsche Geologische Gesellschaft 150/2:195-236

Kendall PF, Briggs H (1933) The formation of rock joints and the cleat of coal. Proc R Soc Edinb 53:164-187

Kessler DW (1919) Physical and chemical tests of the commercial marbles of the United States. Technologic tests of the Bureau of Standards no $123: 54$

Koch A, Siegesmund S (2004) The combined effect of moisture and temperature on the anomalous expansion behavior of marble. Environ Geol 46:350-363

Logan J (2004) Laboratory and case studies of thermal cycling and stored strain on the stability of selected marbles. Environ Geol 46:456-467

Logan JM, Hastedt M, Lehnert D, Denton M (1993) A case study of the properties of marble as building veneer. Int J Rock Mech Min Sci Geomech 30:1531-1537

Márton E, Trajanova M, Zupančič N, Jelen BV (2006) Formation, uplift and tectonic integration of a periadriatic intrusive complex (Pohorje, Slovenia) as reflected in magnetic parameters and palaeomagnetic directions. Geophys J Int 167:1148-1159

Mauko A, Mirtic B, Mladenovic A, Grelk B (2006) Deterioration of the granodiorite façade-case sample Maximarket, Ljubljana. RMZ-Mat Geoenviron 53/1:23-37

Nichols TC Jr (1975) Deformations associated with relaxation of residual stresses in a sample of Barre granite from Vermont. Geol Surv Prof Pap US 875:32

Nordtest Method NT BUILD 499 (2002) Cladding panels: test for bowing. Nordtest project 1443-99/1

Reik G (1976) Residuelle Spannungen in quarzreichen Gesteinen. Röntgendiffraktometrische Messung und Erklärungsmöglichkeiten ihrer Entstehung. Int J Geol Rundschau 65(1):66-83

Richter P, Stettner G (1979) Geochemische und petrographische Untersuchungen der Fichtelgebirgsgranite. Geol Bavaria 78:1129

Rosenholtz JL, Smith DT (1949) Linear thermal expansion of calcite, var. Iceland spar, and Yule Marble. Am Mineral 34:846-854

Sage JD (1988) Thermal microfracturing of marble. In: Marinos PG, Koukis GC (Eds) Engineering geology of ancient works, monuments and historical sites. Balcema, Rotterdam, pp 10131018

Savage WZ (1978) The development of residual stresses in cooling rock bodies. Geophys Res Lett 5:633-636

Scheffzük Ch, Siegesmund S, Nikolayev DI, Hoffmann A (2007) Texture, spatial and orientation dependence of internal strain in marble: a key to understand the bowing of marble panels? Spec Publ Geol Soc Lond 271:237-249 
Siegesmund S, Ullemeyer K, Weiss T, Tschegg EK (2000) Physical weathering of marbles caused by anisotropic thermal expansion. Int J Earth Sci 89:170-182

Strohmeyer D (2003) Gefügeabhängigkeit technischer Gesteinseigenschaften. Dissertation Univ. Göttingen 319 S

Timoshenko SP, Goodier JN (1970) Theory of elasticity, 3rd edn. McGraw Hill, New York, pp 435

Vollbrecht A, Rust S, Weber K (1991) Development of microcracks in granites during cooling and uplift: examples from the Variscan basement in NE Bavaria, Germany. J Str Geol 13(7):787-799

Walther K, Frischbutter A, Scheffzük C, Korobshenko M, Levchanovski F, Kirillov A, Astachova N, Murashkevich S (2005) EPSILON-MDS-a neutron time-of-flight diffractometer for strain measurements. Trans Tech Publ Solid State Phenomena 105:67-70
Widhalm C, Tschegg E, Eppensteiner W (1996) Anisotropic thermal expansion causes deformation of marble cladding. J Perform Construct Facil 10:5-10

Winkler EM (1996) Technical note: properties of marble as building veneer. Int J Rock Mech Min Sci Geomech Abstr 33(2):215-218

Wolter KE (1987) Untersuchung der in situ-Spannung, Residualspannung und der Mikroriß-Systeme in Graniten Süddeutschlands. Dissertation Universität Karlsruhe, $126 \mathrm{~S}$

Zeisig A, Siegesmund S, Weiss T (2002) Thermal expansion and its control on the durability of marbles. In: Siegesmund S, Weiss T, Vollbrecht A (Eds) Natural stone, weathering phenomena, conservation strategies and case studies. Publ Geol Soc Lond 205:65-80

Zupančič N (1994) Petrographic characteristics and classification of Pohorje igneous rocks. Rudarško-metalurški zbornik 41:101-112 (in Slovenian) 